\title{
ABOLISHING MORALITY
}

With hindsight, 1958 emerges as a remarkable year in the recent history of Anglo-American ethics. It was, on the one hand, the year in which Kurt Baier published The Moral Point of View, a book that helped to reestablish a modern tradition in moral philosophy that had been derailed somewhat following Moore. On the other, 1958 was the year in which G. E. M. Anscombe fired her famous broadside against the modern tradition in ethics. 'Modern Moral Philosophy', the lead piece in Philosophy for that year, announced that the very notions moral philosophers had made central since the eighteenth century, "the concepts of obligation, and duty - moral obligation and moral duty, that is to say - and of what is morally right and wrong, and of the moral sense of 'ought', ought to be jettisoned if this is psychologically possible". 1

Just the title of Baier's book was enough to place it squarely within the tradition Anscombe wanted to attack. Indeed, it helped to return to currency the idea that morality has a characteristic point of view, a perspective from which its distinctive notions - moral obligation, moral goodness, and so on - are appropriately recognized and appreciated. And it gave the perspective a name that has stuck.

Anscombe, of course, did not deny that morality involves a characteristic way of viewing human conduct and character. She denied that it is a defensible way. Her thesis was that moral notions are simply incoherent without the obsolete premise of divine law. What is distinctive about morality is the idea of a way of being bound, of moral obligation, which makes no sense at all without the idea of law, with its associated notions of responsibility, guilt, and so on, in the background. But the sort of law required could not be an earthly posit. It could only issue, she argued, from a divine legislator.

Morality involves a "law conception of ethics", and "it is not possible to have such a conception unless you believe in God as a lawgiver".2 Without this assumption the very idea of morality, the notion of a distinctive and authoritative kind of obligation, consideration, motivation, "ought", and so on, is purely vestigial and 
unsupported. "[T]hey are survivals, or derivatives from survivals, from an earlier conception of ethics which no longer generally survives, and are only harmful without it". ${ }^{3}$ If only it were possible, morality should be abolished.

Baier's thesis could hardly have been more starkly opposed. To the claim that morality is based only on superstition, he replied that it can be given a rational basis. The notions of right and wrong do require the idea of rule or "law", as Anscombe had claimed, but the requisite law is not divine. What is needed is the idea of a rule that is "universally teachable" and whose "[o]bservation is for the good of everyone alike". If this is what morality is, if moral obligations are so conceived that it is in the interest of everyone alike that they be regarded as authoritative, then morality has a rational basis - morality's authority derives from reason's. Far from resting on superstition, morality is a construction of practical reason.

With this argument, The Moral Point of View helped to recapture a tradition looking backward to Hobbes, Kant, Hume on the artificial virtues, and Mill on justice, right, and wrong. And, in so doing, it helped to make possible further developments of this line in Rawls, Brandt, Gauthier, and Scanlon, among others. ${ }^{5}$

In the years since 1958 the central concepts of morality, and philosophical attempts to articulate systematic views utilizing them, have hardly vanished from the scene. Far from it. The last twenty-five years have seen a period of remarkably vigorous and fruitful moral philosophizing, perhaps as fruitful as any in this century. But if the tradition represented by Kurt Baier has flourished in the last generation, it must also be recognized that an increasing number of writers have wanted to prune it back in various ways, and for various reasons.

The philosophers $I$ have in mind are not those whose disagreement with Baier has simply concerned, say, the role of rules within a theory of right, or, perhaps, the publicity condition. Act-consequentialists, for example, still share the project of a theory of right, of moral obligation, even if they differ about details. ${ }^{6}$ The writers I have in mind do not. They have thought, at the very least, that modern moral philosophy has been much too focused on notions of moral obligation, right, and wrong.

Some have argued that the virtues and moral emotions are more central to the moral life than can possibly be appreciated so long as one concentrates on obligation. Among other things, moral obligation 
is typically thought to concern specific acts. To focus exclusively on this is both to carve the moral life into artificially discrete units and to miss the emotional element.

Others have argued that relationships of caring for particular others have an import for ethics quite independent of moral obligation. It is no accident, but nonetheless a great mistake, that topics such as love and friendship have only recently come to be discussed again. These are aspects of the moral life one is apt to downplay, if not miss entirely, so long as one's focus is on moral obligation.

But even if these various writers would agree with Anscombe that modern moral philosophy should end its excessive concentration on obligation, almost all would reject, I think, her proposal to abandon the conception completely. Almost all, that is, would reject the call to abolish morality.

I say "almost all" because there is just now one very important exception. Bernard Williams argues in his most recent book, Ethics and the Limits of Philosophy, that morality is "a special system, a particular variety of ethical thought" that "we would be better off without". ${ }^{7}$ Like Anscombe, he advocates abolishing morality.

Indeed, "abolition" would seem just the word Williams wants to associate with his proposal. He titles the chapter containing his indictment, 'Morality, the Peculiar Institution', thereby giving morality the same epithet given to slavery in the antebellum American south. ${ }^{8}$ Taken together with Williams' earlier writings, this allusion may lead one to expect the charge that morality enslaves by alienating a person from his ground projects and so his own integrity. ${ }^{9}$ But though Williams uses the rhetoric of domination liberally, his focus is less on the way morality may dominate individuals and more on the way, as he sees it, it will tend to dominate any other value, whether personal or part of "an ethical life that is to an important degree shared with others" (p. 191). Indeed, he charges, "the morality system ... actually conceals the dimension in which ethical life lies outside the individual" (p. 191).

It is the burden of Williams's abolitionist case that the very idea of morality, with its notions of moral obligation and of a peculiarly "pure" sort of moral motivation, and value attaching to it, involves a "powerful misconception of life" (p. 196), one that, if it gains a foothold, improverishes life by dominance.

In what follows I shall undertake to provide a partial defense of 
morality against Williams' charges. Specifically, I shall argue that the notion of moral obligation is not subject to the defects Williams claims. I shall not, however, be able to take up all of Williams' charges. In particular, I shall not be able to discuss his charge that morality presupposes the illusory idea of a kind of value "that lies beyond all luck" (p. 196).

Of course, even a response to all of Williams' criticisms would not amount to a full justification of morality, not even of moral obligation. But I assume that most people are inclined to think morality, unlike slavery, defensible unless they can be convinced by powerful arguments against it.

I should say in advance that I think Williams' charges are not completely unmotivated. There are many things we have reason to care about as part of a common life other than moral obligation and an ideal of character directly related to it. It is a mistake to try to reduce every ground or motivation for acting to the two categories of the moral and the (merely) personal. ${ }^{10}$ Nonetheless, even if moral obligations are by their nature conceived to be authoritatively overriding, and the moral person conceived to be someone who is governed by them, it does not follow that morality must dominate life in the sense of leaving no place for the embrace and expression of other values. From the fact that morality dominates in the sense that its obligations are conceived to have overriding justificatory weight, it does not follow that it must dominate in the way, for example, someone might dominate a discussion by not allowing others to speak.

MORAL OBLIGATION AND DOMINANCE

Like Anscombe, Williams begins the argument for abolition by tying morality to its special notion of obligation. With one exception that I shall mention below, we may generally accept his characterization. Moral obligations: (a) apply to a person in a situation with respect to an action that, (b) is in the person's power. (c) If a person is under a moral obligation to do something, then the person must, all things considered, do it. And (d), if she does not, she is deserving of reproach (whether or not reproach would be appropriate). Finally, (e) moral obligations are inescapable (pp. 175-177).

Some discussion of this last condition is necessary since Williams 
states it in two different ways. Sometimes what he means is that moral obligations apply to a given agent whether or not he wants them to apply. There is no emigration from morality. But he also expresses the condition in this way: "once I am under an obligation, there is no escaping it..." (p. 177). This can mean something quite different; and for Williams' argument it must. It must mean that once an obligation exists it can never be defeated by any consideration other than an obligation of overriding weight. That moral obligations are inescapable in this sense is, as we shall see, far from clear.

Before we consider Williams' argument, it is worth pausing to consider how these features of moral obligation bring out the ways in which it is modelled on the idea of law. What a person is morally obligated to do is what morality requires her to do. Like legal requirement, moral obligation concerns not what would be advisable, but what one must do. Moreover, violation of moral obligation, failing adequate excuse, constitutes guilt and desert of reproach. And, in both instances, whether a person should be reproached (punished) is a separate question from whether it would be deserved. Finally, because obligations are requirements, violations of which merit reproach, it is only reasonable that they be limited to what people can intentionally do.

Williams' major objection to moral obligation and its place in morality is not Anscombe's that it is simply incoherent without the assumption of Divine law. He does think there is a problem, to which we shall return below, about how moral obligations can bind even those who want not to be bound by them. Nonetheless, his principal concern is that "[i]f obligation is allowed to structure ethical thought, there are several natural ways in which it can come to dominate life altogether" (p. 182). Moral obligation comes to bind us so thoroughly that the moral life becomes one of bondage.

This happens in two interrelated ways, he thinks. First, there is pressure within the "morality system" to represent everything relevant to ethical choice through the prism of its special concept. "It is a mistake of morality to try to make everything into obligations" ( $p$. 180). Moral obligation becomes the dominant category of ethical deliberation.

But if it dominates in this way it will also dominate in a second. The number of things we are obligated to do will so expand that "we may 
begin to get into trouble... finding room for morally indifferent actions" (p. 181). Morality will dominate our lives in the sense that we will be bound by it at every turn.

Now it is not immediately plain why morality must involve either form of dominance. And, actually, Williams never says it must. Rather, he argues that morality has an inherent tendency to dominate. But this claim, though more credible, is more problematic in the context of an argument for abolition. Even if it is true that "dominating" tendencies are inherent in morality, there may be other tendencies, also inherent in morality, that keep them in check.

But why does Williams think that morality has even a tendency to dominate in any sense but the obvious one that it must claim that a moral obligation to do something has overriding justificatory weight? Why does he suppose that morality tends to make every consideration with any justificatory weight at all into a moral obligation and so thoroughly hedge us in?

Williams comes to this conclusion because he thinks that morality "encourages" adherence to two fundamental ideas. First, thinking within the terms of morality leads one to think that if a moral obligation exists, other things equal, to do something, then the only thing that could make it true that there is no moral obligation so to act, all things considered, is a more stringent obligation to act otherwise. Second, if a person has a moral obligation to do something particular in some particular circumstance, that must be because anyone has a general obligation to do that kind of thing. The first idea is expressed in the slogan "only an obligation can beat an obligation". And the second he calls the "obligation-out, obligation-in principle".

The dialectic that leads Williams to these ideas and to moral obligation's unacceptable obtrusiveness is as follows. He begins by describing a situation in which one is under an obligation to visit a friend because of a promise, but then is "presented with a unique opportunity, at a conflicting time and place, to further significantly some important cause" (p. 180). ${ }^{11} \mathrm{He}$ asks us to imagine that the promise and the cause are such that "you may reasonably conclude that you should take the opportunity to further the cause".

So far there is nothing that anyone but an absolutist about promises could not accept. But, Williams argues, there will be a cost. "[O]bligations have a moral stringency, which means that breaking them attracts blame". So "[t]he only thing that can be counted on to cancel 
this, within the economy of morality, is that the rival action should represent another and more stringent obligation". From this he draws the conclusion: "[m]orality encourages the idea, only an obligation can beat an obligation" (p. 180). ${ }^{12}$ In order to hold that one should break a promise one would otherwise be morally obligated to keep to further an important cause, the moralist must then believe there is a more stringent moral obligation to further that cause.

But what does this more stringent conflicting obligation result from? An obligation to further this particular important cause on this particularly propitious occasion could only arise, presumably, because of some more general obligation, perhaps to "assist some important cause on occasions that are specially propitious for assisting it". This, then, is the second idea that morality encourages: any particular moral obligation is backed by a general one. The reasoning leading to a specific moral obligation as conclusion requires a general obligation as premise. Obligation-out, obligation-in.

The cost of accepting there to be cases where one should not do what would otherwise be obligatory is that the moralist must then hold there to be stronger conflicting obligations resulting from fairly powerful general obligations.

And once we have accepted general and indeterminate obligations to further various moral objectives, ... they will be waiting to provide work for idle hands, and the thought can gain a footing (I am not saying that it has to) that I could be better employed than in doing something $I$ am under no obligation to do, and if I could be, then I ought to be. I am under an obligation not to waste time in doing things I am under no obligation to do. ${ }^{13}$

So the real cost to the moralist is that she will then be committed to holding there to be almost no cases where general moral obligations do not plausibly apply. We will always be bound by morality.

There are two important steps in Williams' argument. First, there is the step from the moralist's acceptance of the case to the principle she is "encouraged" to embrace to justify her acceptance: only an obligation can beat an obligation. Second, there is the step from accepting general moral obligations to the obtrusiveness of moral obligation. There is also a step from particular moral obligations to general ones, but it will emerge, I think, that this is not very important by itself. Let us take these two steps one at a time.

Williams is right, surely, to think that both moral common sense and moral theory will want to allow that where one is morally obligated, 
other things equal or "prima facie", to do something, one may not be so obligated all things considered. We may accept his example as such a case. A promise that would otherwise morally obligate may no longer do so in light of a particularly important conflicting objective. ${ }^{14}$ This much is uncontroversial.

But this is only part of the first step. It is also claimed that morality encourages the idea that the only way a prima facie moral obligation can no longer bind in such a case is by virtue of another, more stringent obligation. Thus, to take Williams' case, it is claimed that, given the existence of a prima facie obligation to keep one's promise, the fact that a unique opportunity exists to further significantly some important cause makes it false that one is morally obligated to keep the promise only if there exists a stronger prima facie duty to further the cause.

Now it must be admitted that some moralists have apparently had this picture. Ross is probably the best example, as the language of the last paragraph should remind us. A prima facie duty, for Ross, becomes an actual duty unless there exists some more "incumbent" prima facie duty to act otherwise. ${ }^{15}$ But there seems nothing in the notion of moral obligation to require, or even encourage, this picture. And indeed, moral common sense, and some quite respectable moral theories, explicitly deny it.

To begin with, it is widely accepted that one is not obligated to do many things one would otherwise be morally obligated to do, if doing them would require personal sacrifice, or even sacrifice to loved ones, beyond some rough threshold, even though it would not be wrong to do what would otherwise be obligatory and incur the sacrifice. So, for example, what one is morally required to do by the duty of mutual aid is ordinarily thought to depend on how much sacrifice would be involved. Moreover, it is denied that it would be morally acceptable to fail to make the sacrifice just in case it would be wrong to make it.

Put in the language of prima facie duties, this means that a prima facie duty can be cancelled without being overridden by a more incumbent duty, say, a duty to oneself. It can be defeated by considerations of personal sacrifice. ${ }^{16}$ That this is part of moral common sense seems clear. It is also generally thought, for reasons I shall mention below, to be dictated by rule-consequentialist and rulecontractarian theories of right.

Before we consider Williams' case in this connection, however, let 
us consider a case that is intermediate between his case and the sort of case just discussed. Frances Kamm has crafted a case that brings together features of famous examples of Ross and Judith Thomson. ${ }^{17}$ Suppose A makes a promise to B to meet for lunch. On the way to lunch $\mathrm{A}$ encounters an awful automobile accident whose victim needs aid. (Thus far Ross.) The aid required, as it happens, involves significant personal sacrifice, say, the donation of a kidney. (Thus far Thomson.)

Now, on the one hand, it seems unreasonable to expect $A$ to donate his kidney. The sacrifice involved is sufficiently great that he apparently has no duty to do so. But though he is not morally required to donate his kidney, neither would it be wrong for him to do so were he willing. Far from it. It would be absurd to say that since the only moral obligation $\mathrm{A}$ has is to keep his promise to $\mathrm{B}$, he must keep that promise since it is not overridden by some weightier obligation. Further features of the situation defeat an all things considered moral obligation to keep the promise to $\mathrm{B}$, even if they do not create an overriding obligation to do something else.

Of course, this situation is different from those mentioned earlier. The accident victim's plight does not cancel the obligation to keep the promise in the same way that considerations of personal. sacrifice cancel what would otherwise be an obligation to aid the victim. (Assume the only further help he needs is the kidney.) If A declines to help the victim, he had better keep his promise. The moral complication created for A by the victim's plight is that whereas before he was simply obligated to keep his promise to $\mathrm{B}$, he is now obligated either to do that or to help the victim. He acts wrongly only if he does neither. ${ }^{18}$

It would seem, then, that it can frequently happen that a moral obligation to do something can be cancelled by further features of a situation other than an overriding obligation to act otherwise. What about the sort of case Williams describes, however? Here keeping a promise conflicts with the significant advancement of a cause whose importance is such that it can be "reasonably conclude[d]" that one "should ... further the cause".

Now it must be granted that if the force of "should" is that it would be wrong not to further the cause, then the moralist will of course be committed to the existence of an overriding moral obligation. And just as surely, there will be cases where this would seem just the right 
conclusion to come to. Some causes are sufficiently important that if a significant enough contribution could be made to them without too great a personal cost and at no greater moral cost than a nontrivial, but nonvital, broken promise, it would be wrong not to advance them at that cost.

But not every case where one can reasonably conclude that one should promote a cause rather than keep a promise is one where it would be wrong not to do so. It may be that the situation is that of $\mathrm{A}$ and $B$ above, with the added feature that $A$ is willing to donate his kidney to $B$. Since he is willing to bear the cost, he concludes he should do so; given his priorities that is what would be advisable. But he may also conclude that it is not obligatory since no one could reasonably be expected to bear the cost.

Or it may be that a cause, say a political ideal, or ideal of life to which one is committed, or even the welfare of a friend, is sufficiently important to an individual that not to further it in the requisite way would involve a sacrifice we cannot reasonably expect people to make in furthering their own conceptions of the good. Given its importance to him the individual might reasonably conclude that he is morally permitted to further the cause, and that he should do so and not keep the promise, even though it would not be wrong for him not to do so.

If these possibilities are consistent with morality, then why does Williams think that morality tends otherwise? Why does he think that a prima facie obligation can only be defeated by a more stringent obligation? The reason he gives is that since obligations have a "moral stringency" that consists in their relation to deserved reproach, "the only thing that can be counted on to cancel this" is a rival, more stringent obligation (p. 180). But this feature of moral obligations can be turned against Williams. Surely it is precisely because the violation of a moral obligation is a serious business, making a person liable to blame, that the moralist must be careful not to claim moral obligations to exist beyond what can reasonably be expected of people.

This point has been emphasized by the tradition Kurt Baier represents. If moral obligation is taken to be defined by reproachgoverning rules, the inculcation and teaching of which are "in the interest of everyone alike", there will be a strong case for the sorts of "defeaters" of obligation discussed above. It simply is not in everyone's interests to be considered deserving of reproach if they fail to make efforts beyond some rough level of expected sacrifice. The same 
would seem to be true whether the standard for the rules is that they maximize utility, be choiceworthy from an original position, could not reasonably be rejected by people motivated by the desire for reasonable agreement, or would result from a rational bargain among all.

There will only always seem a need to admit a further obligation to cancel a prima facie one if the moralist fails to keep in mind Williams' own point that an actual moral obligation is an "all things considered" conclusion and not simply one consideration among others in moral deliberation. Williams obscures this when he writes that because of the moral stringency of obligations only a more stringent obligation can be counted on to cancel an obligation. This confuses the "all things considered" moral obligation, violation of which is deserving of reproach, with prima facie obligations. Violating a prima facie obligation appropriately incurs reproach only if other things are equal, and there are more ways other things may be unequal than through the existence of a more stringent rival obligation.

Morality, therefore, neither requires, nor evidently encourages, the first step. Nonetheless, there may well be cases where almost any moralist would hold it wrong, and not simply inadvisable, for a person to fail to break a promise to further a cause. Where does the moralist land if she takes this step? Is she then on a road leading to ubiquitous obligations that partition all, or almost all, choices into the morally required and the morally forbidden?

It is true that once morality recognizes obligations to further causes, even to relieve suffering, it extends the obligatory beyond the range of omissions and voluntarily assumed bonds such as contract. A person cannot then do what is morally obligatory simply by failing to harm or defraud others or to violate agreements he voluntarily made. This will mean that a person's obligations will cease to be within his explicit control in an obvious sense. Mere circumstance can make it true that he morally must do something. A morality with positive obligations is more restrictive than one that lacks them.

But the obligations to render aid, to relieve suffering, to cooperate with others on fair terms, and so on, need not absorb the permissible nor even restrict it unreasonably. Indeed, each can be cast so that a sphere of "agent's prerogative" is maintained if it is understood that they can be defeated by considerations of personal sacrifice beyond some rough level. This is, I believe, how they are understood in moral common sense. And it is the way they are conceived in the tradition 
that sees moral obligations as constituted by "reproach-governing" rules the general acceptance of which is validated by some such standard as "the interest of everyone alike". As far as I can see, the only reason to think morality tends in the direction of ubiquitous obligation is if one really does think that a prima facie obligation can only be cancelled by an overriding obligation.

Interestingly enough, Williams himself believes that we should recognize obligations (he refuses to call them "moral") and correlative rights that one "cannot ignore without blame" (p. 186). Like almost any moralist, he says that obligation "is grounded in the basic issue of what people should be able to rely on" (p. 185). And he includes under this rubric the traditional negative obligations and obligations to aid when the need is "immediate".

How does all this differ in substance from the status that moral obligations are ordinarily thought to have and are accorded by Baier's tradition? The differences one might have expected are simply not there. Williams speaks of the sort of obligation he embraces as having, like moral obligation, "deliberative priority". And he relates obligation to deserved reproach in the same way. In both cases, when an obligation exists, it must be discharged on pain of deserving reproach.

One potential difference concerns the scope of the obligatory. Williams includes only positive obligations that are "immediate". But by itself that need involve no difference in the concept of obligation. And, in any case, Williams admits that "immediacy" is itself a contested concept and that "we must consider what for us, in the modern world, should properly count as immediacy ..." (p. 186).

What Williams really considers to distinguish his proposal from the traditional notion of moral obligation is that it is not committed to the two "principles" of morality: "only an obligation can beat an obligation" and "obligation out, obligation in". If an emergency creates an obligation for A to aid B, "what produces an obligation ... is, precisely, the emergency" (p. 186). We are not required to recognize a general obligation to aid that can only be cancelled by a stronger obligation. But, as I have argued, so much is true for moral obligation also.

I conclude, therefore, that nothing in the idea of moral obligation tends to make it a dominating presence in our lives. This is not to say that no moralists have held moral obligation to dominate in these 
ways, only that there is nothing in the idea of moral obligation that requires or even encourages it. Moral obligations dominate only in the straightforward sense that when they exist morality recognizes no adequate justification for their violation, only excuse.

\section{MORAL OBLIGATION AND AUTHORITY}

Even if moral obligation can be defended against the dominance objection, it may well face problems on other fronts, and Williams thinks that it does. It is central to the idea of moral obligation that it is supposed to be inescapable: it applies to a person whether she wants it to or not. But what does the peculiar authority of morality derive from? How can it bind even those who would not be bound? Why is there no emigration from morality?

It is Williams' view that the idea of an obligation with this sort of authority is illusory. In this concluding section I shall try to indicate how a defense of morality's authority might most successfully be mounted. Williams gives no general argument that morality cannot have the authority it claims. He merely indicates some reasons for being skeptical and issues a challenge. Likewise, I cannot here provide a general argument that moral obligations are inescapable. I shall be content to point to directions in which such an argument might be found.

As Philippa Foot has pointed out, there is an unproblematic, but superficial sense in which moral obligations can be held to be inescapable. ${ }^{19}$ Just as we can think of norms of etiquette as applying to anyone whether they want them to or not, so also can we think of morality. But there is another sense in which we think a person may nonetheless not be obligated by a norm of etiquette even if it applies. So even if we think moral norms apply to everyone, we are not entitled to conclude that a person is thereby genuinely obligated.

But when we reflect on what we mean when we say that someone might not be obligated by a norm of etiquette even if it applies, it seems the only thing we can mean is that he is not morally obligated: that it would not be wrong, perhaps not even prima facie, for him to violate it. ${ }^{20}$ This suggests that when it comes to morality we no longer have any critical space left to consider the possibility that someone might not really be obligated to do what morality requires of him. 
How could a person not really be obligated to do what morality requires if really obligated is morally obligated?

This defense of the no emigration thesis is too facile, however. Even if it is not possible to question whether people are really obligated if they are morally obligated, there are other ways in which the authority of moral claims can be questioned. For one thing, the validity of moral obligation claims can themselves be questioned. Is it ever true that a person is obligated in the way we suppose when we say he is morally obligated? An adequate answer will ultimately require some account of the truth or assertability conditions of moral obligation claims and a showing that at least some moral obligation claims are true and/or assertable with warrant.

Now there are well known problems with providing such an account, but there seem to me to be two main alternatives. One is a moral realism, either of a naturalist or nonnaturalist sort. Naturalist moral realisms seek to discover truth conditions for moral claims in a natural order of which we are a part and with which we can have cognitive, and other causal contact. ${ }^{21}$ Nonnaturalist realists also believe that moral claims have truth conditions, but in an independent moral order that is not a natural order. ${ }^{22}$

Although it is not strictly necessary, moral realisms tend to be externalist. They tend to hold, that is, that a person's being bound by an ultimate principle of obligation is independent of any fact regarding his motivational capacities or whether he would rationally choose, under specified conditions, the principle as binding.

The second main alternative is internalist in this same general sense. It holds that for a person to be morally obligated, it must be the case that the principles by. which he is bound can, in some appropriate sense, spring from him. Within the contractarian tradition, the key idea is that principles of moral obligation are rationally choiceworthy from an appropriate standpoint. ${ }^{23}$

Both of these alternatives are currently being vigorously pursued. Absent a showing that neither can succeed, and that no further alternatives exist, it would be premature to conclude that claims of moral obligation simply cannot have the sort of backing they must have to apply even to would-be emigrees.

So far I have presented these alternatives evenhandedly. There is, however, another aspect of the notion of moral obligation as Williams presents it that may force a choice between them. 
Williams believes that the claim that someone is under a moral obligation is closely connected to the claim that she has thereby a reason so to act. The connection runs, he thinks, through the concept of blame. To be under a moral obligation is to be deserving of blame if one acts otherwise; and blame involves the assumption that the agent could have done otherwise in a strong sense. It assumes not just that she would have if she had chosen, but that she was free to choose in the sense that the choice she is blamed for not making would have been a rational choice for her. It would have been a choice supported by reasons she had.

Now, not all moralists will agree that blame assumes any such thing. But suppose we accept this thesis. Suppose we agree that for an act to be morally obligatory it must be supported thereby by reasons for the agent to act. Are we then committed to Williams' conclusion that "the institution of blame is best seen as involving a fiction, by which we treat the agent as one for whom the relevant ethical considerations are reasons" (p. 193). Is this indeed a fiction?

Two points must be noted. First, Williams distinguishes between there being a reason for someone to act and someone's having a reason to act. Moral obligation claims assume not only that a reason thereby exists, but that the agent has it. Second, whether a person has a reason in the requisite sense depends on his motivational state.

Thus Williams is arguing that blame assumes that the person blamed has reasons in the sense required by an internalist account of reasons. (Note that some moralists who would agree that obligation creates, or is the mark of, reasons to act, will deny this internalist premise.) Blame assumes that the considerations we give in justifying reproach can catch hold of the agent as motivating reasons for him to act. But this threatens the inescapability of moral obligation. For whether a person is really morally obligated will depend on his motivational state.

But we must be careful here. Even if blame presupposes something about the agent's motivational state, it may not presuppose anything that undermines inescapability. To begin with, it seems obvious that in blaming a person we certainly do not assume that his dominant desire is to do what is morally obligatory, or to perform acts with characteristic $M$, where $M$ acts are prima facie obligatory. If there is a connection between blame and assumed motivation it must be much weaker than that.

The only connection that seems plausible is one between blame and 
motivational capacity or susceptibility. Blaming may well seem pointless if the person blamed is simply incapable of responding to it and the considerations given to justify its desert. ${ }^{24}$ But it may be quite consistent with a person's being morally bound only if she has the motivational capacities that give blame point, that whether a person is morally bound is quite independent of whether she wants to be.

Even a person who does not want to be bound by morality may have emotional responses and motivational susceptibilities that are, in some sense, implicitly moral, responses such as resentment, moral indignation, respect, contempt, even blame itself. Moreover, if we regard moral obligation in the rule-contractualist way, this will provide another source of potential motivation. A person may be able to consider whether she would rationally prefer the general acceptance of a rule from a point of view impartial between herself and others, from a moral point of view. ${ }^{25}$ She will then have motivation, from that standpoint, for preferring that people discharge their moral obligations. This, of course, is not the same thing as wanting herself to do what is morally obligatory. But it may lead to that motivation in a natural way; it is a motivational susceptibility that provides some leverage.

Granting that blame requires a connection between moral obligation and potential motivation, then, apparently does not undermine the inescapability of morality. A philosophical account of moral obligation, such as rule-contractualism aims to give, may provide a "demystification" of morality that, nonetheless, does not relegate the connection between moral obligation and reasons to the realm of fiction.

There is the risk, in responding to the sort of attack Williams mounts, of sounding a note of complacency. This would be a mistake. There is much that is problematic both in our ordinary moral ideas and in even our best philosophical accounts of morality. And, as I said at the outset, even an adequate response to all of Williams' objections (which I have not attempted) would not provide a positive justification of morality, or even of moral obligation. My goal has been much more limited. By arguing that several specific objections to the concept of moral obligation can be met, or, at least, that it is far from clear that they cannot be met, I have tried to show that these objections provide little reason to believe that morality is an institution "we would be better off without". 


\section{NOTES}

1 G. E. M. Anscombe: 1958, 'Modern Moral Philosophy', Philosophy 33, 1.

2 G. E. M. Anscombe, p. 6.

${ }^{3}$ G. E. M. Anscombe, p. 1.

${ }^{4}$ Kurt Baier: 1958, The Moral Point of View, Cornell University Press, pp. 195-96, 200.

${ }^{5}$ Rawls remarks in a footnote to his chapter, "The Formal Constraints of the Concept of Right', from A Theory of Justice that "[ $t]$ he account in the text is perhaps closest to that of Kurt Baier in The Moral Point of View". (TJ Harvard University Press, Cambridge, p. 130n.) And the idea that justice (and, Rawls suggests at p. 111, right) is constituted by principles that would be rationally chosen from behind a veil of ignorance has obvious similarities to Baier's view. So likewise do Gauthier and Scanlon's versions of contractarianism. See David Gauthier: 1986, Morals by Agreement, Oxford University Press, Oxford; and Thomas Scanlon: 1982, 'Contractarianism and Utilitarianism', in A. Sen and B. Williams, Utilitarianism and Beyond, Cambridge University Press, Cambridge, pp. 103-28. Brandt's version of rule utilitarianism essentially includes a "teachability" constraint, and, like Baier, Brandt argues that morality has a rational basis, indeed, for him, "right" and "wrong" are to be defined in terms of rules it would be rational to support. "Wrong" is defined as "would be prohibited by any moral code which all fully rational persons would tend to support, in preference to all others or to none at all, for the society". 1979, A Theory of the Good and the Right, Oxford University Press, Oxford, p. 194. For another variation on this general theme, but from a fundamentally internalist orientation, see my Impartial Reason, Cornell University Press, Ithaca, 1983.

6 This must be qualified to some extent since not everyone may mean the same thing by "right". Moore, for example, though he stated his consequentialism with such words as "right" and "duty", made it plain that by these terms he simply meant whatever available act would have the best consequences. If others used the word to refer to an especially authoritative way of being bound that consisted in something different than the simple fact that an act would have the best consequences, including its own intrinsic value if any, then they were free, perhaps, to do so. But there is no such thing. And if that is "right"'s common meaning, then so much the worse for common usage. Moore would then, presumably, simply have restated his view in terms of what it would be best to do.

I detect a strain in some contemporary consequentialists that appears to be in implicit agreement with Moore about this. To the extent that this is so, it is much less clear that these philosophers accept the same basic framework of the tradition Baier represents. 7 1985, Ethics and the Limits of Philosophy, Harvard University Press, Cambridge, p. 174. Further references will be placed parenthetically in the text.

8 Thus Kenneth Stampp's famous study from the 1950's was titled, The Peculiar Institution: Slavery in the Ante-Bellum South.

9 The line of thought to which I refer is one Williams has developed in a number of places, including in J. J. C. Smart and B. Williams, 1973, Utilitarianism: For and Against, Cambridge University Press, Cambridge, pp. 108-18; and 1976, 'Persons, Character, and Morality', in A. Rorty, The Identities of Persons, University of California Press, Berkeley, pp. 197-216. 
${ }^{10} \mathrm{I}$ argue this point within a basically "deontological" framework in 'Right, Reason, and Intersubjective Good', unpublished.

1 One thing that is confusing about Williams' presentation of this case is that he prefaces it by the remark that "we should recall that what is ordinarily called an obligation does not necessarily have to win in a conflict of moral considerations", and then describes the obligation created by the promise as an "everyday obligation". This suggests that it is not an assumption of the case that the person who has promised is under a moral obligation. But if that is not assumed, then it is hard to see what the case is supposed to show, since it is no part of either moral common sense, or moral theory, that only a more stringent obligation in the "everyday sense" can defeat another "everyday" obligation.

12 Note how odd the remark "obligations have a moral stringency..." is if "obligation" is not interpreted as "moral obligation".

13 As I remarked above about Williams' caution in stating that morality only "encourages" but does not require the two fundamental ideas, so here it could be replied on morality's behalf that if the present "thought" does not have to gain a footing, then moral obligations need not dominate life altogether.

${ }_{14}$ It should be noted that this by itself constitutes no commitment to consequentialism.

15 W. D. Ross: 1967, The Right and the Good, Oxford University Press, Oxford, pp. 19-34.

${ }^{16}$ Williams recognizes that this is available in theory but largely dismisses it. In footnote 7 , which appears on p. 222, he acknowledges the possibility that the obligation to keep a promise can be defeated if keeping it would sacrifice "some vital interest". Nonetheless, he claims that for two reasons this will put little pressure on the idea morality encourages: only an obligation can beat an obligation. First, "unless the promise is very trivial, the severe moralist will agree, I suspect, only if the interests involved are indeed vital". And second, in those few cases where the interests of the promisor are thus threatened there will be an obligation of the promissee to release the promisor from his promise.

Both of these replies strike me as odd. First, maybe a "severe" moralist would hold that only vital interests can cancel any but a "very trivial" promise. But that is relevant only if morality encourages severity and Williams can't assume that at this point without begging the question. Also, even if promises are likely to be regarded as almost impervious to defeat by personal considerations (which it seems to me they are not as a general matter), other obligations, for example that of mutual aid, need not be. Second, it is hard to see how the fact that another has an obligation to release one from an obligation is relevant to whether an obligation one has can only be cancelled by being overridden by some weightier obligation one has to do something else.

17 Frances M. Kamm: 1985, 'Supererogation and Obligation', The Journal of Philosophy 82, 119 .

${ }^{18}$ Kamm seems to suggest otherwise since she holds that the only moral duty A has is to keep his promise to B. But that is because she is using "duty" in a different sense than Williams uses "moral obligation". As she is using the term, something may be a duty, even all things considered, without its being true that a person morally must so act. Duties need not be moral requirements. So it is still A's duty to keep his promise though it would not be wrong for him not to. For her reasons for not saying that A's duty becomes disjunctive see op. cit., p. 122. 
${ }^{19}$ Philippa Foot: 1972, 'Morality as a System of Hypothetical Imperatives', Philosophical Review 81, 305-16.

20) Notice also that the idea Williams appeals to in his discussion of emigration, viz., that people ought to be able to renounce their obligations to a particular state by emigration, is itself a moral idea. It includes the claim that there is a moral obligation incumbent on states to make emigration possible, and the claim that emigration defeats moral obligations the person might otherwise have had with, for example, with respect to obeying laws of the state.

${ }^{21}$ For this sort of view see Peter Railton: 'Moral Realism', Philosophical Review, forthcoming. Also see various papers in the "Cornell School": Nicholas Sturgeon: 1985, 'Moral Explanations', in D. Copp and D. Zimmerman, Morality, Reason, and Truth, Rowman \& Allenheld, Totowa, N.J., pp. 49-78; Richard W. Miller: 1985, 'Ways of Moral Learning', Philosophical Review 94, 507-56; and Richard Boyd, 'How To Be a Moral Realist', unpublished.

${ }^{22}$ Moore and Ross are the classical figures here. See Moore, 1966, Principia Ethica, Cambridge University Press, Cambridge.

23 Writers in this tradition, for example, Baier, Rawls, Gauthier, Scanlon, and Brandt, are only all internalist in this very broad sense. It is quite consistent with holding that moral obligation must be rationally justifiable in this way that a person can be morally obligated to do things he cannot be motivated to do. For one thing, it is possible to hold, as Baier does, that rational justification is independent of capacity for motivation.

The proper contrast is not, perhaps, between realism and internalism, as I mentioned above. There are really two contrasts within the class of moral philosophies that would seek to argue, unlike radical noncognitivists, that moral claims have validity conditions of some sort: "nonprocedural" realism vs. constructivism, and externalism vs. internalism.

"Constructivism" is the term Rawls uses to refer to a view that takes the validity of moral claims (he specifically discusses claims of justice) to be procedural in the following sense: their validity depends on the outcome of some ideal procedure or construction: "this kind of view sets up a certain procedure of construction which answers to certain reasonable requirements, and within this procedure persons characterized as rational agents of construction specify, through their agreements, the first principles of justice". (1980, 'Kantian Constructivism in Moral Theory', Joumal of Philosophy, 77, 516.) In contrast with this, a "nonprocedural" realism would hold that moral claims have truth conditions quite independently of what would result from any such procedure.

${ }^{24}$ We need to distinguish here between assumed responsiveness to blame, as such, from responsiveness to concomitants of it: personal rejection, anger, and so on.

${ }_{25}$ This version of contractualism is most congenial to Baier and Rawls. Other contractualisi positions, for example, those of Scanlon and Gauthier, will be associated with different potential motivation.

Department of Philosophy

University of Michigan

Ann Arbor, MI 48109

U.S.A. 